\title{
IMPROVEMENT OF THE RUSSIAN SYSTEM OF STAFF TRAINING IN THE CONDITIONS OF ROBOTIC TECHNOLOGY DEVELOPMENT
}

\author{
Aleksey A. Stepanov \\ Russian University of Economics named after G.V. Plekhanov, Moscow, Russian Federation
}

\begin{abstract}
The main resource of modern manufacturing, agricultural, construction, transport enterprises and also the companies connected with information technologies is their staff. The level of staff training corresponding to the current trends in technology and technologies development, directly defines the level of relevant production industry development and national economy in general.

The development of robotics and the roboti technologies in modern economy has a significant impact on change of the enterprises requirement in human resources and also on change of employers' requirements to professional competences of staff. In the long term, labor market will impose increased requirements to staff on possession of professional competences, on interaction with robotics in a workplace, including the ability to control the equipment, to carry out monitoring of production operations observance and be able to adapt to changes in production process taking into account functionality of robotics. According to various research and polls, the modern system of staff training does not provide the study of such professional competences. In the long term, it can result in discrepancy of the young specialists' competence that completed training in the programs of secondary professional education, and forming the offer in labor market, to those requirements which are imposed from employers. In these conditions transformation of the staff training system which will be focused, first of all, on the formation of those competences which will allow young specialists not only to use the available equipment, but to have an opportunity to master new technologies.

The paper outlines the problem of incompliance of the level of young specialists training and the current trends of robotics development on the basis of statistical data and results of the available research.

Key words: staff, human resources, labor market, professional competences of staff, production efficiency, production operations, innovations, robotics, robotic technology, collaborative robots, kobota, exoskeletons.

Citation. Stepanov A.A. Improvement of the Russian System of Staff Training in the Conditions of Robotic Technology Development. Vestnik Volgogradskogo gosudarstvennogo universiteta. Seriya 3, Ekonomika. Ekologiya [Science Journal of Volgograd State University. Global Economic System], 2019, vol. 21, no. 1, pp. 83-91. (in Russian). DOI: https://doi.org/10.15688/jvolsu3.2019.1.8
\end{abstract}

\section{СОВЕРШЕНСТВОВАНИЕ РОССИЙСКОЙ СИСТЕМЫ ПОДГОТОВКИ КАДРОВ В УСЛОВИЯХ РАЗВИТИЯ РОБОТОТЕХНОЛОГИЙ}

\footnotetext{
Алексей Алексеевич Степанов

Аннотация. Основным ресурсом современных производственных, сельскохозяйственных, строительных, транспортных предприятий, а также компаний, связанных с информационными технологиями, являются рабочие кадры. Уровень подготовки рабочих кадров, соответствующий современным тенденциям в развитии техники и технологий, напрямую определяет уровень развития соответствующей отрасли производства и экономики страны в целом. Развитие робототехники и робототехнологий в современной экономике оказывает существенное воздействие на изменение потребности предприятий в человеческих ресур-
} 
cax, a также на изменение требований работодателей к профессиональным компетенциям рабочих кадров. В перспективе рынок труда будет предьявлять к рабочим кадрам повышенные требования по владению профессиональными компетенциями взаимодействия с робототехникой на рабочем месте, включая умение производить настройку, калибровку оборудования, осуществлять мониторинг соблюдения производственных операций, а также способность адаптироваться к изменениям в производственном процессе с учетом функционала робототехники. Современная система подготовки рабочих кадров не обеспечивает формирование у обучающихся подобных профессиональных компетенций, о чем свидетельствуют результаты различных исследований и опросов. В перспективе это может привести к несоответствию компетенции молодых специалистов, завершивших обучение по программам среднего профессионального образования и формирующих предложение на рынке труда, тем требованиям, которые предъявляются со стороны работодателей. В данных условиях требуется трансформация системы подготовки рабочих кадров, которая будет ориентирована на формирование прежде всего тех компетенций, которые позволят молодым специалистам не только пользоваться имеющейся техникой, но иметь возможность освоить новые технологии.

В статье обозначена проблема несоответствия уровня подготовки молодых специалистов современному состоянию и тенденциям развития робототехники и робототехнологий с помощью статистических данных и результатов имеющихся исследований.

Ключевые слова: кадры, человеческие ресурсы, рынок труда, профессиональные компетенции рабочих кадров, эффективность производства, производственные операции, инновации, робототехника, робототехнологии, коллаборативные роботы, коботы, экзоскелеты.

Цитирование. Степанов А. А. Совершенствование российской системы подготовки кадров в условиях развития робототехнологий // Вестник Волгоградского государственного университета. Серия 3 , Экономика. Экология. - 2019. - T. 21, № 1. - С. 83-91. - DOI: https://doi.org/10.15688/jvolsu3.2019.1.8

\section{Постановка проблемы}

В современной рыночной экономике большое внимание уделяется развитию робототехники. Робототехника и робототехнологии находят широкое применение в промышленности, сельском хозяйстве, информационных технологиях, строительстве, транспорте, связи. Обозначенные отрасли экономики привлекают значительную долю сотрудников, квалификация которых относит таковых к рабочим кадрам.

Под рабочими кадрами автор понимает работников, способных к самостоятельной деятельности по решению практических задач, требующих самостоятельного анализа ситуации и ее изменений; участвующих в управлении решением поставленных задач в рамках подразделения; способных нести ответственность за решение поставленных задач или за результат деятельности группы работников подразделения. С точки зрения автора, рабочие кадры обладают компетенциями по решению различных типов практических задач с элементами проектирования, выбору способа решения в изменяющихся условиях рабочей ситуации, текущему и итоговому контролю, оценке и корректировке деятельности.
Данный подход сформирован автором на основе уровней квалификации, разработанных в целях проектирования профессиональных стандартов (уровни квалификации утверждены приказом Минтруда России от 12 апреля 2013 г. № 148н [6]).

Рабочие кадры в условиях развития технологий производства и появления новых отраслей экономики должны трансформироваться в категорию тех работников, которые способны выполнять инженерные функции и обладают актуальными техническими и прикладными знаниями для работы на передовом производственном оборудовании [2; 3; 7]. Рабочие кадры являются объектами управленческого труда руководителей и специалистов организации и выполняют роль основных носителей и источников резервов организации в сокращении доли бракованной продукции, снижении потерь от производственных срывов, росте производительности труда и уменьшении себестоимости готовой продукции. Таким образом, от категории рабочих кадров во многом зависит конкурентоспособность организации на рынке. Соответственно, актуальным вопросом для современных организаций и предприятий является вопрос подготовки рабочих кадров. 


\section{Оценка потребности предприятий в рабочих кадрах и основные проблемы их подготовки}

Федеральная служба государственной статистики по состоянию на 31 октября 2016 г. фиксирует потребность в работниках различного уровня квалификации в объеме $2,2 \%$ от общего количества рабочих мест (см. таблицу). Данный мониторинг проводится один раз в два года. Таким образом, ожидаем официальное опубликование данных о потребности организаций в работниках различного уровня квалификации за 2018 г. в I квартале 2019 года.

При этом удельный вес потребности в рабочих кадрах составляет 57,3\% от общего числа вакантных рабочих мест. Данные, приведенные в таблице, демонстрируют заинтересованность экономики в рабочих кадрах.

Подготовка рабочих кадров в России осуществляется за счет реализации образовательных программ среднего профессионального образования (далее - СПО) [8]. Исходя из данных, приведенных на рисунке 1 , можно сделать вывод о неудовлетворенности работодателей качеством профессиональных навыков недавних выпускников программ СПО (отметили недостаток 58 \% работодателей), умением решать возникающие в ходе работы пробле- мы (отметили недостаток 23,5 \% работодателей), способностью работать самостоятельно (отметили недостаток 22 \% работодателей).

Менее всего претензий высказали работодатели к навыкам у недавних выпускников программ СПО по работе с компьютером $(0 \%)$, знаниям иностранных языков $(0,5 \%)$, способности к обучению (5 \%), способностям взаимодействия с людьми $(8,5 \%)$, способности к инициативе (11,5 \%). Таким образом, абсолютное большинство работодателей отмечают недостаточность профессиональных навыков у недавних выпускников программ СПО, что ставит вопрос соответствия содержания и качества подготовки обучающихся по программам СПО требованиям современного рынка труда. Для решения данного вопроса проводится множество научных исследований, реализуются государственные программы повышения качества подготовки рабочих кадров, осуществляется мониторинг мирового опыта подготовки рабочих кадров в целях последующего его внедрения в отечественной практике.

Для современного работодателя первостепенное значение при принятии решения о трудоустройстве выпускника программ СПО имеют такие факторы, как уровень подготовки, разряд и степень, личные качества и навыки кандидата, опыт работы (см. рис. 2). Та-

Таблииа

Потребность организаций в работниках для замещения вакантных рабочих мест по профессиональным группам на 31 октября 2016 г.

\begin{tabular}{|l|c|c|c|}
\hline \multicolumn{1}{|c|}{ Категория } & $\begin{array}{c}\text { Списочная чис- } \\
\text { ленность работни- } \\
\text { ков - всего, чел. }\end{array}$ & $\begin{array}{c}\text { Потребность в ра- } \\
\text { ботниках для за- } \\
\text { мещения вакант- } \\
\text { ных рабочих мест, } \\
\text { чел. }\end{array}$ & $\begin{array}{c}\text { Удельный вес по- } \\
\text { требности в работ- } \\
\text { никах для замеще- } \\
\text { ния вакантных ра- } \\
\text { бочих мест, \% }\end{array}$ \\
\hline Всего специалистов & 27837803 & 637621 & 2,2 \\
\hline Руководители & 2517820 & 27052 & 1,1 \\
\hline Специалисты высшего уровня квалификации & 7300525 & 173984 & 2,3 \\
\hline Специалисты среднего уровня квалификации & 3071644 & 89953 & 2,8 \\
\hline $\begin{array}{l}\text { Служащие, занятые подготовкой и оформлени- } \\
\text { ем документации, учетом и обслуживанием }\end{array}$ & 1277605 & 28656 & 2,2 \\
\hline $\begin{array}{l}\text { Работники сферы обслуживания и торговли, ох- } \\
\text { раны граждан и собственности }\end{array}$ & 2520454 & 68960 & 2,7 \\
\hline $\begin{array}{l}\text { Квалифицированные работники сельского и } \\
\text { лесного хозяйства, рыбоводства и рыболовства }\end{array}$ & 242208 & 4866 & 2,0 \\
\hline $\begin{array}{l}\text { Квалифицированные рабочие промышленности, } \\
\text { строительства, транспорта }\end{array}$ & 4168287 & 102896 & 2,4 \\
\hline $\begin{array}{l}\text { Операторы производственных установок и ма- } \\
\text { шин, сборщики и водители }\end{array}$ & 3539261 & 69711 & 1,9 \\
\hline Неквалифицированные рабочие & 3199999 & 71534 & 2,2 \\
\hline
\end{tabular}

Примечание. Составлено по: [4]. 


\section{УПРАВЛЕНИЕ ЭКОНОМИЧЕСКИМ РАЗВИТИЕМ}

ким образом, усилия, принимаемые на уровне государства, отраслевых ведомств и конкретных образовательных организаций по повыше- нию качества подготовки рабочих кадров, ориентированы на требования рынка труда «сегодняшнего дня», что, с точки зрения автора,



Рис. 1. Результаты анкетирования работодателей по оценке недостающих навыков у молодых специалистов - выпускников программ среднего профессионального образования в России Примечание. Составлено по: [5].

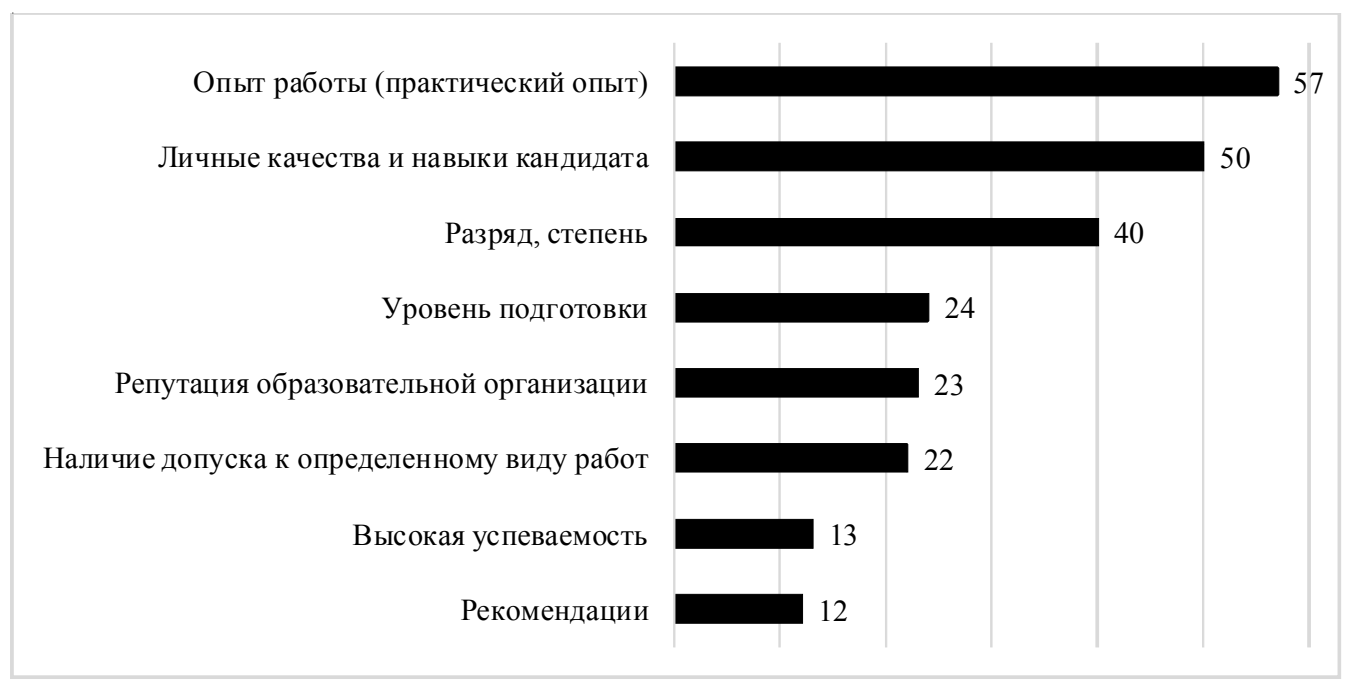

Рис. 2. Факторы принятия решений работодателем при рассмотрении возможности трудоустройства недавнего выпускника программ СПО на предприятие

Примечание. Составлено по: [5]. 
является недостаточным. Перед системой подготовки рабочих кадров стоит глобальная задача - провести трансформацию подходов и содержания к подготовке рабочих кадров, учитывающих не только актуальное состояние рынка труда, но и перспективные изменения. В противном случае система подготовки рабочих кадров не перестанет быть отсталой от требований работодателей, а значит будет способствовать сохранению издержек предприятий-работодателей на переобучение вновь принятых рабочих кадров.

\section{Динамика и основные направления развития робототехнологий в России}

В этой связи важно обратить внимание на стремительное развитие робототехнологий. Объемы производства и ввода в эксплуатацию промышленных роботов в мире растут в геометрической прогрессии. В соответствии с прогнозами агентства IFR ожидается рост мирового эксплуатационного парка промышленных роботов с 1828 тыс. ед. в 2016 г. до 3053 тыс. ед. в 2020 году.

Ежегодная рыночная стоимость установленных промышленных роботов в 2020 г. составит порядка 23,2 млрд долл., что на 280 \% больше показателя 2011 года (рис. 3) [1].

Рост количества промышленных роботов, введенных в эксплуатацию, непременно сказывается на потребности организаций в рабочей силе. Данное влияние выражается в сокращении потребности работодателей в человеческих ресурсах благодаря автоматиза- ции производственных операций. Помимо сокращения количественной потребности, робототехнологии формируют новые подходы работодателей к качеству рабочей силы, то есть диктуют требования к профессиональным компетенциям работников.

Согласно данным аналитического исследования Сбербанка в 2016 г. 91 \% всех мировых промышленных роботов были задействованы в отраслях обрабатывающей промышленности [1]. Установлено, что основными потребителями промышленных роботов являются автомобилестроение (35\%), электрика и электроника (31\%), металлургия (10\%), химическая промышленность (7 \%), пищевое производство (3 \%) (см. рис. 4). Внедрение робототехники в промышленное производство способствует замещению человека при выполнении операций сварки и спайки, разлива, напыления, дозирования, обработки, резки, фрезеровки, шлифовки, сборки и разборки, запрессовки, монтажа, перемещения, упаковки и др. [1].

Таким образом, рабочие кадры, занятые выполнением данных видов операций на рабочих местах в организациях, вынуждены оперативно адаптироваться к условиям совместной работы с роботами. Адаптация, с точки зрения автора, подразумевает либо обучение и приобретение соответствующих компетенций для выполнения иных видов трудовых функций, где робототехника в данный момент не применяется, либо приобретение компетенций, способствующих эффективной совместной работе с роботами, а также компетенций

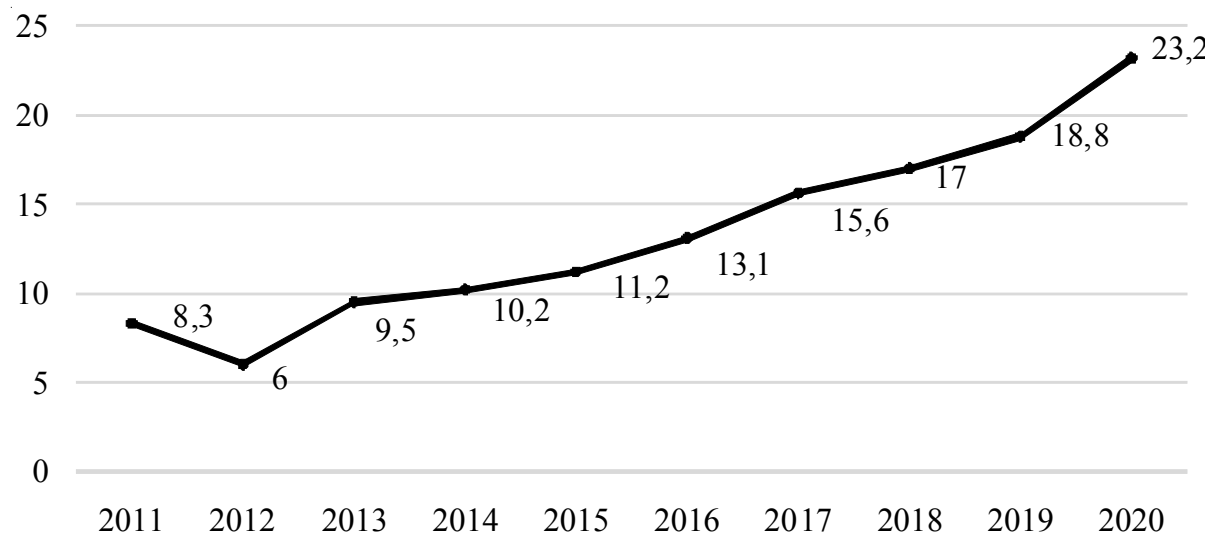

Рис. 3. Примерная ежегодная рыночная стоимость установленных промышленных роботов в мире, млрд долл. Примечание. Составлено по: [1]. 


\section{УПРАВЛЕНИЕ ЭКОНОМИЧЕСКИМ РАЗВИТИЕМ}

по их управлению и обслуживанию. Наиболее перспективным направлением адаптации, с нашей точки зрения, является второй вариант. В этой связи актуально рассмотреть вопрос развития и широкого распространения коллаборативной робототехники, представляющей собой новое направление в развитии промышленной робототехники.

\section{Развитие}

\section{коллаборативной робототехники}

\section{как нового направления промышлен-} ной робототехники

Определение коллаборативного робота (кобота) дано в ISO 15066:2016 и означает робота, сконструированного для непосредственного взаимодействия с человеком в рам- ках определенного совместного рабочего пространства [9]. Особенностями коботов, выражающих их преимущество и объясняющих стремительное распространение коллаборативной робототехники в промышленном производстве, являются возможности безопасной работы рядом с человеком, легкость монтажа и настройки, низкая стоимость по сравнению с традиционными роботами.

При этом объемы поставок коллаборативных роботов растут интенсивными темпами (рис. 5), что означает увеличение спроса на данные технологии. Приведенная динамика поставок и выручки от продаж коботов в период 2015-2025 гг. позволяет сделать вывод о широком распространении в промышленном производстве коллаборативной робототехники и неизбежном изменении требова-



Рис. 4. Распределение поставок промышленных роботов по отраслям обрабатывающей промышленности в 2016 г. в мире

Примечание. Составлено по: [1].



Рис. 5. Ожидаемые объем поставок и выручка от продаж коллаборативных роботов в 2015-2025 гг. в мире Примечание. Составлено по: [1]. 
ний к профессиональным компетенциям рабочих кадров, задействованных на предприятиях соответствующих отраслей обрабатывающей промышленности.

Помимо коллаборативной робототехники, важную роль в изменении требований к профессиональным компетенциям рабочих кадров играют и промышленные экзоскелеты - активные механические приборы с выраженными антропоморфными свойствами, подходящими по размеру оператору, который его эксплуатирует, и работающими согласованно с движениями оператора [1]. Данное инновационное направление в робототехнике особенно актуально в промышленном производстве, где рабочие кадры выполняют особо сложные технологические процедуры, связанные с двигательной активностью, применением силы, скоростью и синхронностью выполнения операций.

Объемы реализации промышленных экзоскелетов до 2020 г. демонстрирует стабильное увеличение спроса промышленного сектора экономики на данные технологии (рис. 6). Внедрение экзоскелетов в промышленное производство играет существенную роль в облегчении условий труда рабочих кадров и обеспечивает решение главной задачи - эргономичной поддержки для уменьшения нагрузки на опорно-двигательную систему человека, а также повышения уровня безопас- ности для человека при выполнении им трудовых операций.

Среди типовых задач, в решении которых применяются коллаборативные роботы и экзоскелеты, выделяются перемещение объектов, сортировка объектов, упаковывание, обработка материалов и сборка электроники [1]. Участие человека в выполнении данных производственных задач не исключается полностью. Смысл взаимодействия человека с данными робототехнологиями при выполнении производственных операций заключается в снижении физической и эмоциональной нагрузки на человека, а также уровня риска производственного травматизма за счет выполнения некоторых процессов коботами. Экономический эффект от такого взаимодействия достигается за счет роста производительности труда, снижения объемов выбраковываемой продукции, системного обеспечения более высокого качества продукции и снижения потребности в рабочей силе предприятия. При этом работник, осуществляющий выполнение производственных функций с участием кобота и экзоскелета, должен обладать навыками взаимодействия с данными системами, заключающимися в умении производить настройку, калибровку, осуществлять мониторинг соблюдения производственных операций, а также быть способным адаптироваться к изменениям в производственном процессе с учетом

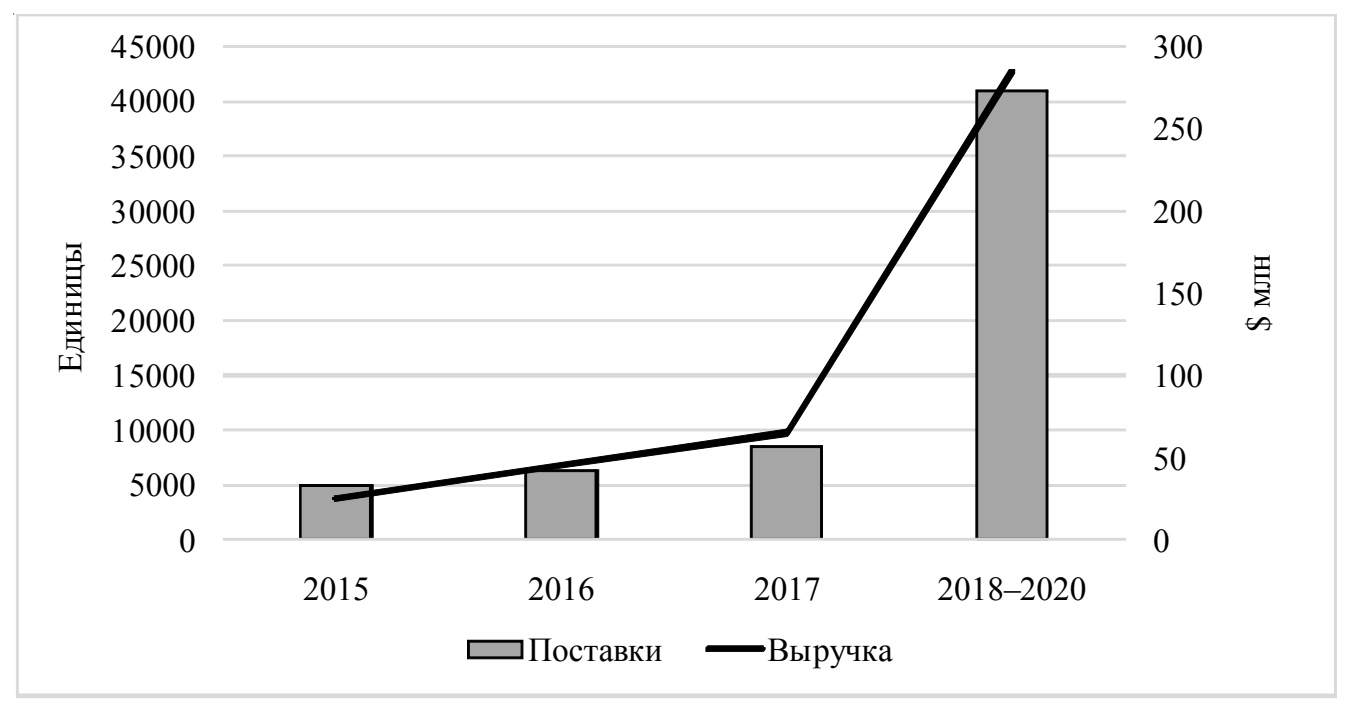

Рис. 6. Фактические и ожидаемые объемы поставок и выручка от продаж промышленных экзоскелетов в 2015-2020 гг. в мире

Примечание. Составлено по: [4]. 
функционала коллаборативного робота и экзоскелета. Анализ федеральных государственных образовательных стандартов среднего профессионального образования, утвержденных в России, показал полное отсутствие предусмотренных профессиональных компетенций, что означает неподготовленность выпускников программ СПО к выполнению трудовых функций на рабочем месте с привлечением робототехники.

\section{Заключение}

Подводя итог, автор приходит к выводу, что стремительное развитие робототехнологий в промышленной сфере неминуемо приводит не только к сокращению потребности предприятий в человеческих ресурсах, но и к существенному изменению требований промышленного производства к профессиональным компетенциям рабочих кадров. При этом актуальная система подготовки рабочих кадров в данный момент не приспособлена к формированию у обучающихся тех профессиональных компетенций, которые позволили бы стать востребованными рабочими кадрами «завтрашнего дня», что означает необходимость продолжения трансформации данной системы.

\section{СПИСОК ЛИТЕРАТУРЫ}

1. Аналитический обзор мирового рынка робототехники, 2018 // Лаборатория робототехники Сбербанка. - Электрон. текстовые дан. - Режим доступа: http://www.sberbank.ru/common/img/ uploaded/analytics/2018/analiticeskij-obzormirovogo-rynka-robototehniki.pdf (дата обращения: 01.11.2018). - Загл. с экрана.

2. Бузский, М. П. Основные стратегии развития образования в современной России / М. П. Бузский // Теория, методика и воспитание в современном образовательном пространстве : материалы Междунар. науч.-практ. конф., Волгоград / Волгоградский филиала ФГБОУ ВО «Российский экономический университет им. Г.В. Плеханова»; под общ. ред. А. Н. Бурова. - Волгоград : Сфера, 2018. C. $8-15$.

3. Буров, А. Н. Модернизация образования и формирование современной личности / А. Н. Буров // Воспитание студенческой молодежи: методология, теория, практика : материалы науч.-практ. конф., Волгоград, 24 декабря 2010 г. Ч. 1 / Комитет по образованию и науке Администрации Волгоградской области, Волгоградская обществ. организация «Отлично». - Волгоград : Сфера, 2011. C. 3-8.

4. Выборочное обследование организаций Федеральной службы государственной статистики «О численности и потребности организаций в работниках по профессиональным группам», 2016. Электрон. текстовые дан. - Режим доступа: http:// www.gks.ru/wps/wcm/connect/rosstat_main/rosstat/ ru/statistics/publications/catalog/doc_1245749635312 (дата обращения: 11.11.2018). - Загл. с экрана.

5. Мониторинг экономики образования // Информационно-аналитические материалы по результатам социологических обследований Высшей школы экономики. - 2018. - Вып. 7 (73). - 7 с. Электрон. текстовые дан. - Режим доступа: https:// memo.hse.ru/data/2018/04/03/1164822215/ iam_7_2018(73).pdf(дата обращения: 10.12.2018). Загл. с экрана.

6. Приказ Минтруда России от 12 апреля 2013 г. № 148н «Об утверждении уровней квалификации в целях разработки проектов профессиональных стандартов». - Дата публикации: 05 июня 2013 г. - Электрон. текстовые дан. - Режим доступа: http:// www.garant.ru/products/ipo/prime/doc/70266852/ (дата обращения: 10.12.2018). - Загл. с экрана.

7. Профессиональная социализация студенческой молодежи : монография / Е. В. Басистая, Ю. В. Дильман, И. С. Дмитриева [и др.]. - Волгоград : Волгогр. науч. изд-во, 2014. - 193 с.

8. Утемов, В. В. Компетентностная модель обучения в колледже при реализации ФГОС среднего профессионального образования / В. В. Утемов // Концепт. - 2015. - № 11 (ноябрь). - С. 91-95.

9. ISO/TC 299 Robotics - "ISO/TS 15066: 2016 Robots and robotic devices - Collaborative robots", 2016. - Electronic text data. - Mode of access: https:/ /www.iso.org/stand-ard/62996.html. - Title of screen.

\section{REFERENCES}

1. Analiticheskiy obzor mirovogo rynka robototekhniki, 2018 [Analytical Review of the World Robotics Market, 2018]. Laboratoriya robototekhniki Sberbanka [Laboratory of Robotics of Sberbank]. URL: http://www.sberbank.ru/common/img/uploaded/ analytics/2018/analiticeskij-obzor-mirovogo-rynkarobototehniki.pdf (accessed 1 November 2018).

2. Buzskiy M.P. Osnovnye strategii razvitiya obrazovaniya v sovremennoy Rossii [The Main Strategies of Education Promotion in Modern Russia]. Burov A.N., ed. Teoriya, metodika $i$ vospitanie $v$ sovremennom obrazovatelnom prostranstve: 
materialy Mezhdunar. nauch.-prakt. konf., Volgograd [The Theory, Methodology and Education in Modern Educational Space: Materials of the International Scientific and Practical Conference, Volgograd]. Volgograd, Sfera Publ., 2018, pp. 8-15.

3. Burov A.N. Modernizatsiya obrazovaniya i formirovanie sovremennoy lichnosti [Modernization of Education and Formation of the Modern Personality]. Vospitanie studencheskoy molodezhi: metodologiya, teoriya, praktika: Materialy nauchno-prakticheskoy konferentsii, 24 dekabrya 2010 g., Volgograd. Ch. 1 [Education of Students: Methodology, Theory, Practice: Materials of the Scientific and Practical Conference, December 24, 2010, Volgograd. Part 1]. Volgograd, Sfera Publ., 2018, pp. 3-8.

4. Vyborochnoe obsledovanie organizatsiy Federalnoy sluzhby gosudarstvennoy statistiki "O chislennosti $i$ potrebnosti organizatsiy $v$ rabotnikakh po professionalnym gruppam», 2016 [Selective Inspection of the Organizations of the Federal State Statistics Service 'On the Number of Organizations and Their Requirement for Professional Workers', 2016]. URL: http://www.gks.ru/wps/wcm/connect/rosstat_main/ rosstat/ru/statistics/publications/catalog/ doc_1245749635312 (accessed 1 November 2018).

5. Monitoring ekonomiki obrazovaniya [Monitoring of Education Economy]. Informatsionnoanaliticheskie materialy po rezultatam sotsiologicheskikh obsledovaniy Vysshey shkoly ekonomiki [Information and analytical materials by results of sociological inspections of Higher School of Economics], 2018, iss. (73). 7 p. URL: https://memo.hse.ru/ data/2018/04/03/1164822215/iam_7_2018(73).pdf. (accessed 10 December 2018).

6. Prikaz Mintruda Rossii ot 12 aprelya $2013 \mathrm{~g}$. № 148n «Ob utverzhdenii urovney kvalifikatsii v tselyakh razrabotki proektov professionalnykh standartov», 2013 [Order of the Ministry of Labour and Social Protection of the Russian Federation of April 12, 2013 No. 148n 'About the Approval of Skill Levels for Development ofDraft Professional Standards', 2013]. URL: http://www.garant.ru/products/ipo/prime/doc/ 70266852/ (accessed 10 December 2018).

7. Basistaya E.V., Dilman, Yu.V., Dmitrieva I.S., et al. Professionalnaya sotsializatsiya studencheskoy molodezhi: monografiya [Professional Socialization of Student's Youth: Monograph]. Volgograd, Volgogradskoe nauchnoe izd-vo. 2014. 193 p.

8. Utemov V.V. Kompetentnostnaya model obucheniya v kolledzhe pri realizatsii FGOS srednego professionalnogo obrazovaniya [Competence-Based Model of Training in College at Realization of FGOS of Secondary Professional Education]. Kontsept, 2015, no. 11, pp. 91-95.

9. ISO/TC 299 Robotics - "ISO/TS 15066: 2016 Robots and robotic devices - Collaborative robots", 2016. URL: https://www.iso.org/stand-ard/ 62996.html.

\section{Information about the Author}

Aleksey A. Stepanov, Director of the Center for Work with Branches, Russian University of Economics named after G.V. Plekhanov, Stremyanny Lane, 36, 117997 Moscow, Russian Federation, StepanovRGtU@yandex.ru, https://orcid.org/https://orcid.org/0000-0002-8642-0641

\section{Информация об авторе}

Алексей Алексеевич Степанов, директор Центра по работе с филиалами, Российский экономический университет имени Г.В. Плеханова, Стремянный пер., 36, 117997 г. Москва, Российская Федерация, StepanovRGtU@yandex.ru, https://orcid.org/0000-0002-8642-0641 